\title{
INNOVATIVE USE OF ICT IN EARLY YEARS CURRICULUM BASED ON 5E INSTRUCTIONAL MODEL
}

\author{
Christina Kalaitzi ${ }^{1}$, \& Christina Volioti ${ }^{2}$ \\ ${ }^{1}$ Department of Early Childhood Education, Aristotle University of Thessaloniki (Greece) \\ ${ }^{2}$ Department of Applied Informatics, University of Macedonia (Greece)
}

\begin{abstract}
Active learning constitutes an essential part of the early years curriculum. A well-known instructional model which is based on active participation and inquiry learning is the 5E model which includes the following five stages a) Engage, b) Explore, c) Explain, d) Elaborate, and e) Evaluate. Moreover, over the last decades ICT has been widely used to engage students in learning and enhance both the learning and teaching process. However, a paradox is noted regarding ICT; although practitioners have commonly accepted the beneficial aspect of ICT, they demonstrate limited use of new technologies within the teaching process. Therefore, the present work proposes a methodological approach aiming to investigate, whether the incorporation of the 5E model into ICT activities could benefit the use of new technologies in the early years curriculum. A pilot study was performed on early years practitioners in kindergartens. For the purposes of the current experiment, an ICT-based activity was designed using the 5E model. The activity's layout, including the objectives and the learning outcomes, is outlined. The main benefits, according to practitioners, are that the $5 \mathrm{E}$ model not only provides multiple opportunities for students to build new knowledge through inquiry and active engagement, but also enhances practitioners' confidence in terms of using and integrating ICT into the teaching process. This result, despite being preliminary, indicates that the integration of ICT activities through the 5E model can be an effective approach. Lastly, since this is an on-going study, more results will be published in the near future.
\end{abstract}

Keywords: ICT, early years curriculum, 5E instructional model, inquiry learning, engagement.

\section{Introduction}

Nowadays Information and Communications Technologies (ICT) has become an important medium for learning across the early years curriculum. However, there seem to be certain limitations regarding the incorporation of ICT tools into the teaching process (Brooker, 2003) and, therefore, a clear need of a developed pedagogy for the use of technology has been reported (Aubrey \& Dahl, 2013). The present research proposes the methodology of the implementation of an ICT activity integrating the $5 \mathrm{E}$ instructional model. The objective of the pilot study is to explore whether the $5 \mathrm{E}$ model affects the students' active participation and engagement into the learning process of ICT.

\section{Literature review}

\subsection{Early years practitioners' attitude towards the integration of ICT within the teaching process}

Brooker and Siraj-Blatchford (2002), in their large scale study of effective pedagogy across the curriculum for the early years, showed that technology appears to stimulate children of differing abilities, levels of maturity as well as ethnic and social class backgrounds. Results indicated that children were found to engage in lively and supportive collaborative activities around the computer, with particular linguistic and cognitive gains and social development for bilinguals. Despite the uncontested benefits of ICT, the study showed that computers were being used in a limited way and that practitioners rarely engaged in the type of interactions with children. This draws the attention to the fact that the rapid growth in curriculum requirements, and in hardware, has not always been matched by a growth in practitioners' understanding of appropriate ways to use the new technologies.

Although Brooker (2003) pointed out that practitioners working with young children were willing to match new technologies with traditional early childhood goals and principles, aiming at a child-initiated and child-centered, exploratory and open-ended, learning, that would be supportive of 
social interactions and of equal opportunities there were certain limitations, such as a) a reliance on desktop computers as the sole tool for technology, when a range of other applications (i.e. projectors) may be more appropriate, b) a preference for didactic software that teaches curricular materials (i.e. literacy, numeracy) through closed questions, rather than exploratory software that allows children to pose their own questions and discover their own answers, c) a trend towards situating computers in suites or laboratories, segregating them from all other aspects of the curriculum. Moreover, a small-scale investigation of the confidence, competence and views regarding use of ICT by a maximum variation sample of practitioners, showed that although all practitioners identified technologies available in their center (most commonly mentioned were computers, educational software, Internet, electronic and programmable toys and the interactive whiteboard), they said that they knew very little about ICT and indicated a fear of technology (Aubrey, 2013).

Plowman and Stephen (2003) conclude that while practitioners believe in the benefits of computers, these are more likely to come about when staff feel able to use resources discriminately to match children's learning needs and styles as well as their own theories of learning. Aubrey and Dahl (2013) provided evidence in support of that assumption further adding that there is a need to identify different models for providing effective support and pooling of existing skills and resources. These observations point to the need not only for a more developed pedagogy for the use of computers in the classroom but also for practitioners to have opportunities to become more familiar with the software available. Furthermore, practitioners need to be encouraged to be more critical about whether or not the learning model inherent in the software used, matches both their own models of learning and the needs of the children for whom they are responsible.

\subsection{The 5E Instructional Model: Engaging students in new concepts learning}

Bybee et al. (2006) translated decades of research into a brief and memorable set of five words that educators could actually use, the $5 \mathrm{E}$ Model which is an inquiry-based approach grounded in active learning. The $5 \mathrm{E}$ model is based on a conceptual change model of learning, where learners become receptive to new ideas and then integrate new information into their existing conceptual framework (Posner, Strike, Hewson \& Gertzog, 1982). The 5E approach is grounded in a constructivist view of learning, where the students have to do the work of identifying and changing their conceptions (Vygotsky, 1978). More specifically, the five components of the 5E model are the following: (1) The ENGAGEMENT, where the students' prior knowledge is identified in order to become engaged in a new concept. (2) The EXPLORATION, where they use prior knowledge to generate new ideas, to explore questions and possibilities. (3) The EXPLANATION, where they focus attention on a particular aspect of their engagement and exploration experiences and demonstrate their conceptual understanding, process skills, or behaviors. (4) The ELABORATION, where they develop and extend their skills and apply their understanding of the concept. (5) The EVALUATION, where they are encouraged to assess their understanding and abilities, and where their progress is evaluated towards achieving the learning objectives.

The fact that the $5 \mathrm{E}$ model is structured in five distinctive components, following a linear sequence, each one building on the knowledge of the other, might be considered as an established methodology enabling the educator not only to design, organize and implement ICT activities, but also to identify and assess the children's learning.

\subsection{The objective of the current research}

Although there is plenty of research showing the use of the $5 \mathrm{E}$ model into the science domain, very limited research is found regarding its incorporation into the ICT field (Utari et al., 2013). Taking this into consideration the present work explores whether the proposed methodological approach of the $5 \mathrm{E}$ model affects the implementation of ICT into the early years curriculum. The aforementioned general hypothesis is followed by two sub questions:

RQ1.1. Does the 5E model offer opportunities for students to build new knowledge through inquiry and active engagement?

RQ1.2. Does the $5 E$ model affect the use and integration of ICT into the teaching process on behalf of the practitioners?

\section{Methodology}

\subsection{Framework}

An intervention was designed especially for the purposes of the present research that was based on the objectives of the Greek New Curriculum (Institute of Educational Policy, 2014), concerning the learning area of Information and Communications Technologies. The activity layout includes five phases, 
each covering a separate component of the 5E model while integrating the others at the same time. Since, the early years curriculum implementation relies on the principles of constructivism, which is also applied to the instructional 5E model, the activity's layout attributes a fundamental role to variations of constructivism, such as inquiry-based learning, active learning and knowledge building (DeVries, Zan, Hildebrandt, Edmiaston \& Sales, 2002). In Table 1, the design of the ICT activity is presented while integrating the $5 \mathrm{E}$ instructional model.

Table 1. The ICT activity layout integrating the $5 E$ instructional model.

\begin{tabular}{|c|c|}
\hline \multicolumn{2}{|r|}{ ACTIVITY LAYOUT } \\
\hline TITLE & Live Wishing Cards \\
\hline $\begin{array}{l}\text { GENERAL } \\
\text { PURPOSE }\end{array}$ & $\begin{array}{l}\text { - Development and expression of ideas with digital media and the production of multimodal works } \\
\text { - Reinforcement of learning experiences with the use of ICT (Institute of Educational Policy, 2014) }\end{array}$ \\
\hline $\begin{array}{l}\text { SPECIFIC } \\
\text { OBJECTIVE } \\
\text { S }\end{array}$ & $\begin{array}{l}\text { - To become familiar with the basic forms of digital information (text, image, sound) } \\
\text { - To develop and express ideas using digital media } \\
\text { - To [allow children to] express themselves in a creative way with the use of designing software, and } \\
\text { the use of audio/image/video editing and recording (Institute of Educational Policy, 2014) }\end{array}$ \\
\hline $\begin{array}{l}\text { LEARNING } \\
\text { AREAS }\end{array}$ & $\begin{array}{l}\text { - Information and Communications Technologies } \\
\text { - Language } \\
\text { - Art (Institute of Educational Policy, 2014) }\end{array}$ \\
\hline DURATION & 5 days (one phase per day) \\
\hline AGE GROUP & 5-6 years (kindergarten) \\
\hline $\begin{array}{l}\text { NUMBER OF } \\
\text { STUDENTS }\end{array}$ & 18-20 (average class) \\
\hline 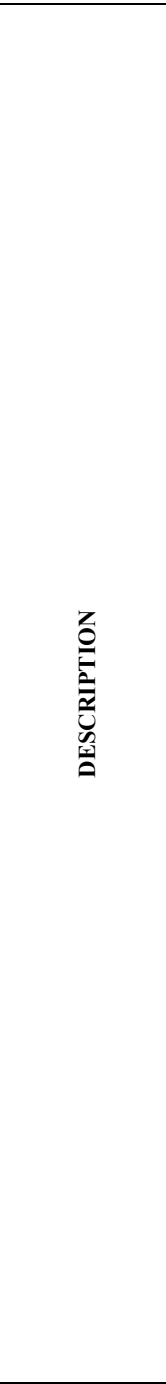 & 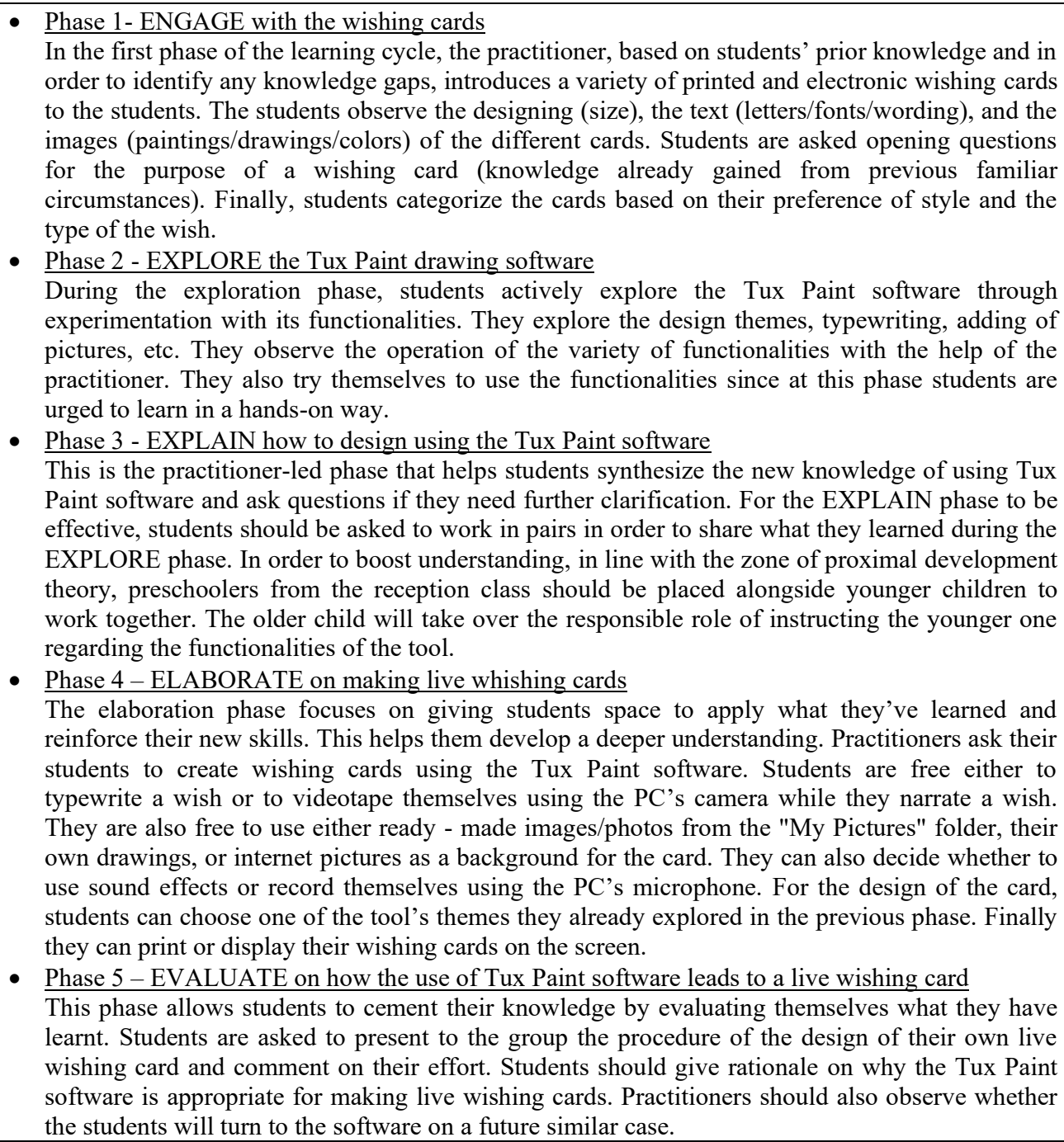 \\
\hline $\begin{array}{l}\text { LEARNING } \\
\text { OUTCOMES }\end{array}$ & $\begin{array}{l}\text { Students are expected to: } \\
\text { - operate design software through the use of different options from the tools available } \\
\text { - incorporate the gradual use of various software in their practices } \\
\text { - } \quad \text { express themselves in a creative way while acquiring new ICT skills }\end{array}$ \\
\hline
\end{tabular}


Practitioners were asked to perform the ICT activity of "Live Wishing Cards" based on their existing professional experience without the use of the $5 \mathrm{E}$ model and its phases (pre intervention). Following that, they implemented the particular ICT activity -designed by the authors-, following the five phases which incorporate the 5E model and report on the results (post intervention). After the implementation of each of the two interventions, a questionnaire was distributed to the practitioners in order for them to describe the impact of the 5E model integration to the ICT activity, its effects on students' participation and their engagement with the process.

\subsection{Research design}

The questionnaire was developed by the authors for the purposes of this research and some questions were based on Lund's (2001) questionnaire for measuring ICT usefulness and satisfaction. It included twenty four $(\mathrm{n}=24)$ 5-point Likert scale questions, ranging from $1=$ Strongly Disagree to 5 = Strongly Agree and the questions were grouped into two thematic areas: 1) students' active participation and engagement, which contains the following groups: a) engage, b) explore, c) explain, d) elaborate and e) evaluate; and 2) ICT use and integration into the teaching process on behalf of the practitioners. The instrument's reliability is reasonably high (Cronbach's alpha $=0.95)$. Finally, a small scale study was conducted and seven $(n=7)$ early years practitioners (range, 18-21 years) participated by fully completing the questionnaire.

\section{Results and discussion}

The purpose of the present study was to examine whether the incorporation of the 5E model into ICT activities could affect the use of new technologies in the early years curriculum. Firstly a descriptive statistical analysis was performed, presenting means and standard deviations for the question groups of the pre and post intervention (Table 2).

Table 2. Means (M), Standard Deviations (SD) and P-values for the question groups of the pre and post intervention.

\begin{tabular}{|c|c|c|c|}
\hline & \multicolumn{3}{|c|}{ Early years practitioners $(n=7)$} \\
\hline & Pre intervention $M(S D)$ & Post intervention $M(S D)$ & P-value \\
\hline \multicolumn{4}{|c|}{ 1. Students' active participation and engagement } \\
\hline ENGAGE & $3.00(1.26)$ & $4.48(0.51)$ & $<0.001$ \\
\hline EXPLORE & $1.76(0.62)$ & $4.24(0.62)$ & $<0.001$ \\
\hline EXPLAIN & $2.00(0.89)$ & $4.33(0.65)$ & $<0.001$ \\
\hline ELABORATE & $1.86(0.65)$ & $4.24(0.70)$ & $<0.001$ \\
\hline EVALUATE & $1.57(0.50)$ & $4.14(0.73)$ & $<0.001$ \\
\hline \multicolumn{4}{|c|}{ 2. ICT use and integration into the teaching process } \\
\hline PRACTITIONERS & $2.29(1.03)$ & $3.92(0.86)$ & $<0.001$ \\
\hline
\end{tabular}

In general, Table 2 indicates that the level of scores in post intervention were higher than in pre intervention in all question groups. Therefore to further examine the changes in pre and post intervention, a series of Wilcoxon signed rank tests were performed, where the p-values of question groups are presented in Table 2. Wilcoxon signed rank test was selected since the sample size was small $(n=7)$ and the difference between the scores were not normally distributed. More precisely:

RQ1.1. Does the 5E model offer opportunities for students to build new knowledge through inquiry and active engagement?

The Wilcoxon S-R test showed a statistically significant change between the pre and post intervention in the first part of questionnaire, which includes the following five question groups: engagement, exploration, explanation, elaboration and evaluation. Analytically, the proposed ICT activity, integrated with the $5 \mathrm{E}$ model, engaged and further stimulated the students to actively participate in the activity $(Z=-3.601, \mathrm{p}<0.001)$ when compared to the situation before the integration of the $5 \mathrm{E}$ model. Additionally, students explored the ICT tool in greater depth $(Z=-4.165, p<0.001)$ and explained their experience and knowledge thoroughly by connecting what they already knew with the current activity $(Z=-3.964, p<0.001)$. Finally, they applied their acquired knowledge effectively $(Z=-4.104, p<0.001)$ and evaluated it adequately $(Z=-4.136, p<0.001)$. From the aforementioned findings, it is confirmed that the scores are higher in post intervention than in pre intervention, eliciting statistical significance in all question groups. The incorporation of the 5E model into the ICT activity shows that a child-initiated and child-centered lesson plan stimulates each student's active participation and inquiry-based learning providing a peer interaction in every phase. The explanatory, open-ended and collaborative nature of the $5 \mathrm{E}$ model enhances the achievement of early childhood goals and principles, 
since it is built on pre-existing knowledge and leads to acquiring new cognitive skills (Brooker, 2003; Brooker \& Siraj-Blatchford, 2002; Posner et al., 1982; Vygotsky, 1978).

RQ1.2. Does the $5 E$ model affect the use and integration of ICT into the teaching process on behalf of the practitioners?

With respect to this question, on behalf of the practitioners, the implementation of the $5 \mathrm{E}$ model into the ICT activity helped them to be more effective and productive as well as to have more control over the implementation of the ICT activity $(Z=-6.058, p<0.001)$. The aforementioned findings reinforce that the $5 \mathrm{E}$ model, as a developed methodology of five coherent and consecutive phases, could enable the early years practitioners to meet the children's learning needs through a developed pedagogy, which according to the previous research (Aubrey \& Dahl, 2013; Plowman \& Stephen, 2003), has arisen as an instant need. The phases of the 5E model enable not only students to explore the ICT concept, but also the practitioners to become familiar with new technology tools. In the end of the procedure practitioners also have the opportunity to be critical and reflective of the learning outcomes.

\section{Conclusions}

In conclusion, the purpose of this particular research was to explore whether the incorporation of the 5E model could affect the use of ICT tools in the early years curriculum. A small scale pilot study was conducted on early years practitioners and a pre and post intervention was performed. Leveraging the statistical analysis, the first indicative results show that the integration of the 5E model into the ICT activities enable practitioners to follow a developed methodology which lead to specific learning outcomes and students to engage in inquiry learning simultaneously. The aforementioned study is preliminary and along with the small scale intervention study, further investigation and research should be undertaken in the near future. The forthcoming work aims, using a larger number of participants, to measure thoroughly the effect of the 5E model into a wide range of ICT activities. The larger sample and the long term intervention should give safer and broader results and attempt to answer further questions regarding how the innovative use of ICT in early years curriculum can be affected by the $5 \mathrm{E}$ instructional model.

\section{References}

Aubrey, C., \& Dahl, S. (2013). The confidence and competence in information and communication technologies of practitioners, parents and young children in the Early Years Foundation Stage. Early Years, 34(1), 94-108.

Brooker, L. (2003). Integrating New Technologies in UK Classrooms Lessons for Teachers from Early Years Practitioners. Childhood Education, 79(5), 261- 267.

Brooker, L., \& Siraj-Blatchford, J. (2002). "Click on Miaow": How children of three and four years experience the nursery computer. Contemporary lssues in Early Childhood, 3(2), 251-273.

Bybee R. W., Taylor J. A., Gardner A., Van Scotter P., Powell J. C., Westbrook A., \& Landes N. (2006). The BSCS 5E instructional model: origins, effectiveness, and applications. Colorado Springs: BSCS.

DeVries, R., Zan, B., Hildebrandt, C., Edmiaston, R., \& Sales, C. (2002). Developing Constructivist Early Childhood Curriculum: Practical Principles and Activities. Early Childhood Education Series. New York: Teachers College Press.

Institute of Educational Policy. (2014). $21^{\text {st }}$ Contemporary school - New Curriculum (Horizontal Act MIS: 295450, Subcontract 1 "Implementation of Curriculum in Compulsory Education"). Athens: Hellenic Ministry of Education and Religious Affairs.

Lund, A. M. (2001). Measuring Usability with the USE Questionnaire. Usability and User Experience Newsletter of the STC Usability SIG, 8(2).

Plowman, L., \& Stephen, C. (2003). A "benign addition"? Research on ICT and pre-school children. Journal of Computer Assisted Learning, 19, 149-164.

Posner, G. J., Strike, K. A., Hewson, P. W., \& Gertzog, W. A. (1982). Accommodation of a scientific conception: towards a theory of conceptual change. Science Education, 66, 211-227.

Siraj-Blatchford, I., Sylva, K., Muttock, S., Gilden, R., \& Bell, D. (2002). Researching Effective Pedagogy in the Early Years. DfES research report 356. London: DfES.

Utari, S. S, Alfiani, A, Feranie, S, Aviyanti, L, Sari, I. M., \& Hasanah, L., (2013). Application of learning cycle 5e model aided Cmaptools-based media prototype to improve student cognitive learning outcomes. Applied Physics Research, 5(4), 69-76.

Vygotsky, L. S. (1978). Mind in Society: The Development of Higher Mental Processes. Cambridge, MA: Harvard University Press. 